\title{
Interferon-gamma (IFN $\gamma$ ) in macrophage activation syndrome (MAS) associated with systemic juvenile idiopathic arthritis (sJlA). High levels in patients and a role in a murine mas model
}

\author{
Claudia Bracaglia ${ }^{*}$, Ivan Caiello ${ }^{1}$, Kathy De Graaf ${ }^{2}$, Giovanni D'Ario², Florence Guilhot ${ }^{2}$, Walter Ferlin², Lidia Melli', \\ Giusi Prencipe ${ }^{1}$, Sergio Davi ${ }^{3}$, Grant Schulert ${ }^{4}$, Angelo Ravelli ${ }^{3}$, Alexei Grom, Cristina De Min², \\ Fabrizio De Benedetti ${ }^{1}$
}

From 21st European Pediatric Rheumatology (PReS) Congress

Belgrade, Serbia. 17-21 September 2014

\section{Introduction}

IFN $\gamma$ is the pivotal mediator in murine models of primary HLH.

\section{Objectives}

Given the similarities between primary and secondary (sHLH), including MAS, we analyzed IFN $\gamma$ levels in patients with sJIA and MAS and evaluated the pathogenic role of IFN $\gamma$ in a murine MAS model.

\section{Methods}

We measured levels of IFN $\gamma$, IFN $\gamma$-related chemokines (CXCL9, CXCL10, CXCL11), and IL-6 in patients with sHLH $(n=14)$, and in patients with sJIA $(n=54)$ of whom 20 had MAS at sampling using the Luminex multiplexing assay and evaluated their relation to disease activity. The effect of the anti-IFN $\gamma$ antibody XMG1.2 was assessed in IL-6 transgenic (IL6TG) mice in which a MAS-like syndrome leading to death is triggered by TLR ligands (Strippoli, Arthritis Rheum 2012). An LPS LD50 (5 $\mu \mathrm{g} / \mathrm{gr}$ body weight) was used, as a trigger for MAS, followed 10 hours later by administration of $100 \mu \mathrm{g} / \mathrm{gr}$ of XMG1.2.

'Division of Rheumatology, Department of Pediatric Medicine, IRCCS Ospedale Pediatrico Bambino Gesù, Rome, Italy

Full list of author information is available at the end of the article

\section{Results}

Levels of IFN $\gamma$ and of IFN $\gamma$-related chemokines [median $\mathrm{pg} / \mathrm{ml}(\mathrm{IQR})]$ were markedly elevated in active MAS and active sHLH, with no significant differences between active sHLH [IFN $\gamma$ 34.7(23.9-170.1); CXCL9 33598 (3083-127687); CXCL10 4420(799.7-8226); CXCL11 1327(189-2000)] and active MAS [IFN $\gamma$ 15.4(5.1-52.6); CXCL9 13392(2163-35452); CXCL10 1612(424.8-4309); CXCL11 564.8(197.5-1007)]. Levels in active sJIA without MAS at sampling [IFN $\gamma$ 4.88(3.2-8.7); CXCL9 836.5 (470.9-2505); CXCL10 307.3(198.9-693.7); CXCL11 121.7(62-197.1)] were lower (all p-values $<0.01$ ) than in active sHLH or active MAS. IL-6 was not different between the three groups. In active MAS, platelet count was inversely related to IFN $\gamma(\mathrm{r}=-0.53 ; \mathrm{p}=0.02)$, CXCL9 $(\mathrm{r}=-0.51 ; \mathrm{p}=0.03)$ and CXCL10 $(\mathrm{r}=-0.58 ; \mathrm{p}=0.009)$. In the murine MAS model, treatment with the anti-IFN $\gamma$ antibody XMG1.2 resulted in increased survival (XMG1.2treated 10 survivors/10 treated; control-treated 5/10; $\mathrm{p}=0.033)$.

\section{Conclusion}

IFN $\gamma$, and IFN $\gamma$-related chemokine levels were increased in patients with MAS compared to patients with active sJIA without MAS, and associated with low platelet count. Neutralization of IFN $\gamma$ increased survival in murine MAS. 


\section{Disclosure of interest}

None declared.

\section{Authors' details}

${ }^{1}$ Division of Rheumatology, Department of Pediatric Medicine, IRCCS

Ospedale Pediatrico Bambino Gesù, Rome, Italy. ${ }^{2}$ Novimmmune SA, Plan-lesOuates, Geneva, Switzerland. ${ }^{3}$ University of Genoa, Istituto Giannina Gaslini, Genoa, Italy. ${ }^{4}$ Division of Pediatric Rheumatology, Cincinnati Children's Hospital Medical Center, University of Cincinnati College of Medicine, Cincinnati, Ohio, USA.

Published: 17 September 2014

doi:10.1186/1546-0096-12-S1-O3

Cite this article as: Bracaglia et al:: Interferon-gamma (IFN $\gamma$ ) in macrophage activation syndrome (MAS) associated with systemic juvenile idiopathic arthritis (sJIA). High levels in patients and a role in a murine mas model. Pediatric Rheumatology 2014 12(Suppl 1):O3.

Submit your next manuscript to BioMed Central and take full advantage of:

- Convenient online submission

- Thorough peer review

- No space constraints or color figure charges

- Immediate publication on acceptance

- Inclusion in PubMed, CAS, Scopus and Google Scholar

- Research which is freely available for redistribution

Submit your manuscript at www.biomedcentral.com/submit 